THE LOGIC OF PASSION 



\title{
THE LOGIC OF PASSION
}

\section{THE LITERARY CRITICISM $\mathrm{OF}$ WILLIAM HAZLITT}

\author{
JOHN L. MAHONEY
}

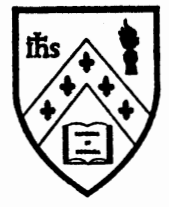

New York

Fordham University Press

I 98 I 
(C) Copyright 1978 by John L. Mahoney

(C) Copyright 198 I by Fordham University Press

All rights reserved

LC $81-67501$

ISBN 0-8232-1073-I (clothbound)

ISBN 0-8232-1074-X (paperback)

Preliminary edition 1978

Revised edition 1981 
To

John, Pat, and Bill, my continuing sources

of

inspiration 
All quotations of Hazlitt's writings are taken from The Complete Works of William Hazlitt, ed. P. P. Howe, 21 vols. (London: Dent, 1930-1934). 